\begin{tabular}{c} 
Volume and Issues Obtainable at Center for Sustainability Research and Consultancy \\
Journal of Business and Social Review in Emerging Economies \\
ISSN: 2519-089X \& ISSN (E): 2519-0326 \\
Volume 7: Issue 4 December 2021 \\
¿SRᄃ \\
Journal homepage: www.publishing.globalcsrc.org/jbsee \\
\hline
\end{tabular}

\title{
Queen Bee Syndrome a Part of Sexual Politics or another Gendered Stereotype
}

Ramish Mufti, Lahore Institute of Science \& Technology, Lahore, Pakistan

Amani Moazzam, Institute of Administrative Sciences, University of the Punjab, Lahore, Pakistan

*Abdul Basit, Lahore Institute of Science \& Technology, Lahore, Pakistan

*Corresponding author's email: abasit_shahbaz@yahoo.com

\begin{tabular}{l}
\hline ARTICLE DETAILS \\
\hline History \\
Revised format: Nov 2021 \\
Available Online: Dec 2021 \\
\hline
\end{tabular}

Keywords

Queen Bee Syndrome,

Female Leaders, Female

Staff, Stereotype, Banking

Sector

JEL Classification

$M 1, M 2$

\section{ABSTRACT}

Purpose: The aim of the study is to explore the queen bee stereotype in the financial institutions running its operations in Pakistan since there has been seen an increase in the trend of participation of women in the commercial banks.

Design/Methodology/Approach: Using a qualitative research methodology, the lived experiences of the female at leadership position and their subordinates are explored; by recognizing the factors of phenomena of queen bee syndrome as well as the sexual politics prevalent in the banking industry.

Findings: The results highlighted that the phenomena of queen bee is a gender based stereotype along with being a part of the sexual politics which is taking place in the banking sector since it is a sector having domination of male. The study also found that there is female to female acceptance and female leaders help their fellow women to grow in the banking sector.

Implications/Originality/Value: The study is beneficial to all the stakeholders and provides a clear insight about the predominant dynamics in females working in the same organization but at different position which results in eliminating the perpetuation of biases within female staff members regarding the women leaders.

(C) 2021 The authors, under a Creative Commons Attribution-

NonCommercial 4.0

Recommended citation: Mufti, R., Moazzam, A. and Basit, A. (2021). Queen Bee Syndrome a Part of Sexual Politics or another Gendered Stereotype. Journal of Business and Social Review in Emerging Economies, 7 (4), 835-846.

\section{Introduction}

The world population is constituted by the women is almost 49.58\% (Statistics Times, 2021). The statistics of Pakistan Bureau is indicated that total population of male in Pakistan is $106.018 \mathrm{~m}$, the number of female is $101.344 \mathrm{~m}$ and the population of the transgender stands at 321,744 (Desk, 2021). The total percentage of male is $50.8 \%$, female is $49.2 \%$ and the transgender form $0.24 \%$ in Pakistan population (Countrymeters, 2021). The labour market rate is $51 \%$ of total employment to population in which the ratio of female is almost $21 \%$ as compared 
to rate of male that is $30 \%$, whereas the rate of female in the education and workplace is increasing with a slow trend (Statistics, 2018). Unfortunately, the female are still underrepresented in Pakistan as the number of female at top positions of leadership in the firms and politics is scarce (Webber \& Giuffre, 2019). Due to the type cast of glass ceiling, the leadership is considered to be associated with male instead of female, this stereotype is resulting in reducing opportunities for female to perform the tasks of frontrunners (Baumgartner \& Schneider, 2010). However, female leaders can contribute to the firm in a positive way by her capabilities and skills and also give chance to the fellow female staff to grow (Glass \& Cook, 2016). When the female are placed positioned as frontrunners, the inequality in gender will reduce and the female subordinates will be treated in an encouraging way for their growth. But it has negative consequences too that female at leadership positions in a male dominant workplace use the hard style that creates a phenomenon of queen bee. The phenomena of queen been has been emerging as a stereotype at universal level. The female at upper position distance themselves from the other female staff which decrease the success opportunities for subordinate women (Faniko et al., 2021). So this assumption is proving that it is not male who are holding back the female staff but it is the female supervisors who are repressing their development and pushing them back instead of encouraging them (Derks et al., 2016). This kind of mentality is increasing the biasness regarding gender and creates a disparaging environment for women henceforth gives raise to stereotypical mindset for female (Glass \& Cook, 2016). The phenomena of queen bee is an individual natural desire to conquer the other individual by attaining power and influence (Arvate et al., 2018). Baumgartner and Schneider (2010) revealed that female as a leader distance herself from the fellow females and shows an uncooperative and obstructive behavior at the workplace so the female subordinate give the label of queen bee to the female leader. But the literature review lacks evidence about the style of female leader towards male staff and influence of the environment on giving such label to the women at upper level as well as the views and perceptions of the female staff members who have a women leader at the top managerial position (Piccio, 2021). There is a need to explore the stereotype that whether the female leaders are nourishing fellow females or influencing the chances of growth and development for them. The study in hand has two fold objective first to explore the phenomena of queen bee as a stereotype linked with the women leaders and second to study the experiences of the female staff and the female leaders in the banking sector of Pakistan. Additionally, the research also examines the role of environment of the organization in reducing the gender inequality or it is dominance of male which believes that when female who are working together they become rivals to each other. Furthermore, the study shed light on effect of the phenomena of queen bee and its prevalence in the banking sector of Pakistan. To be more specific, following are the research questions:

$\boldsymbol{R Q 1 :}$ What is the influence of female on the female co-worker at workplace?

RQ2: What is the level of willingness of female for working with the female colleagues?

RQ3: What are the main reasons behind labeling the female leaders as queen bee?

RQ4: What is the experience of the female who are working with the women in banking institution at different managerial ranks?

Remaining part of the article is structured as: literature review, theoretical framework, methodology, data analysis, discussion and conclusion.

\section{Literature Review}

Before embarking on the analysis of the phenomenon under study, it is pertinent to appraise the profusion of published research literature. Google is used as search engine to appraise survey of literature and explored the renowned research data bases of Taylor \& Francis, Springerlink, Jstor, Elsevier (Science Direct), Wiley-Blackwell, Emerald, etc. using key words: queen bee, queen bee syndrome, queen be stereotype, female leaders, female staff, stereotype, queen bee in 
banking sector, gender inequality and gender discrimination. It is important to document the efforts made by different researchers across the globe to set the context of the current study. The terminology of queen been was first presented by Staines, Travis and Jayaratne in 1974. Queen bee is referred as a pejorative label which is given to the female who have achieved success and became a leader in a work place that is male dominant and such female have a suppressing behavior towards their female staff (Arvate et al., 2018). The phenomena is explaining that women having an ambitious attitude holds a perception of working like men and superior than other female staff, therefore, female leaders distance themselves from the subordinate women at the work setting (Faniko et al., 2021). It is also explained as female leaders who tries to improve their professional opportunities in the firms ruled by men through dwindling success chances for the female subordinates. The leadership styles of the females at numerous management positions are different while it is compared with the male managers. Particularly, female uses authoritative and transformational style of leadership (Scheifele et al., 2021). The stereotype of queen bee indicates that female encumbers the development of other female and shows stiffness regarding their advancement. As the representation of the female has amplified over the past years in the managerial levels which is encouraging the other female at the work setting nonetheless it is not assuring that the women and men are receiving equal rights at the workplace (da Rocha Grangeiro et al., 2021). Formanowicz (2021) argued that the phenomena of queen bee does not exist in the personality of the women but this myth is assumed in the workplace setting as well as in the matter of promoting the women. Drexler (2013) claimed that the results of numerous research studies showed that the staff members prefer men supervisors as compared to female because the traits of a successful leader that are self-confidence, decisiveness and proficiency mismatch the traits of female that are graciousness, nervousness and balminess. Consequently, in contrast to the women traits, the male traits are strappingly linked with the veracious managerial position. This is one of the reason that female are facing glass ceiling and less chances of promotion and when they are promoted such labels are given to them (Babalola et al., 2021). The results of the past research conducted in the professional fields highlighted that the lower level of personnel articulated negative remarks, less trustworthy and snub actions about the female bosses (Harvey, 2018). In contrast to the female, the male managers receive negative as well as positive responses. Subsequently, the behavior and conduct of the female leader is influenced that also effects the performance of the organization as mentioned in the literature. The female at leadership position is stereotyped and considered to make absurd decision (Fleischer, 2021). The previous research study concluded that when the female at upper position come across any kind of stereotypical intimidation in the workplace, their inclination to acquire manly characters increase and she tends to have a dominant, authoritative, hostile and commanding demeanor due to which female leaders are considered to be queen bee (da Rocha Grangeiro et al., 2021). The stereotypical snags are giving raise to the phenomena of queen bee (Derks et al., 2011a). Ebrahim (2021) revealed that the women are labeled as queen bee because of the issue of gender discrimination because when women face discernment and still reached at the top position she opt for the culture of queen bee. By studying the existing literature, it has been observed that male in authority likely to oppose the coworkers instead of supporting in contrast to the female who help and promote their colleagues. Kobus-Olawale et al. (2021) argued that if any individual is involved in a culture that is hostile and intimidating he/she learn that values and when come in power those learned ethics are applied by him/her. The culture of queen bee is pursued by older age female since they have more gender based conduct (Derks et al., 2011b). It has been also deliberated that when female achieve an eminent rank, she consider herself superior from the junior female and contradict the existence of sexism in the firm (Sengul et al., 2019). Another element which is giving raise to the culture of queen bee is the factor of jealousy between the associates because of the negative stereotype and the environment of the company (Derkset al., 2016). The rivalry among the female in the firm creates fear of losing the particular rank such circumstance includes entrance of new employee, performance of the personnel or merger of the divisions (Corwin et al., 2021). Netshitangani (2021) asserted that female subordinates are more 
efficient than women supervisors and the conflict in both grades is natural. The two different groups of Alpha male and queen bee was studied, the results indicated that both groups has high level of manly individualities compared with women staff members and both have competitive behavior (Piccio, 2021). Crisp of literature presented has built the base to conceptualize and to present the phenomena rather more systematic and rigorous.

\section{Theoretical Framework}

The female subordinate deals with the queen bee culture by presenting themselves with a strong gender identity of womanly characters and differentiate themselves from the women supervisors and they are labeled as Princess bee. Thus, the queen bee is threatened by the women subordinates and connect with them. The theory of group socialization explains the behavior and expectations of the members of group and individuals which is developing the culture of queen bee in a negative way (Levine \& Moreland, 1994). When the process of socialization is linked with the management ranks it leads towards mainstreaming of labor force so consequently, the beliefs and goals of the subordinate women are vanished that reinforce male philosophies (Billing \& Alvesson, 1989). Keeping in view the social role conception at macro level, the roles of female and male are different. The social role of male is considered to be bread winner and source of income while the women are expected to be involved in the domestic chores. Talking about the communal characters of both genders at micro level such as in the organization, male are linked with having the skills needed to be at the managerial position while women are predicted to be emotive and nurturer. Accordingly, the female adopt the culture of queen bee for the purpose to express her managerial abilities (Krause \& Hartney, 2021). The theory of social identity is related with the myth of queen bee, that the identity of the individuals is established on the gender (Stets \& Burke, 2000). So, when a female is positioned at an upper level, it creates negative stereotypes against their identity as the women are considered to be jealous of other females (Kasem, 2021). The theory also states that when the individual stays at minority class in a company they learn their characteristics and same is the case with the female when they attain an upper level position in result they opt for culture of queen bee (Sengul et al., 2019). According to the role incongruity theory, there are two patterns of gender stereotype outlined that is descriptive and prescriptive (Eagly \& Karau 2002). The descriptive stereotype illustrates that beliefs shared by the female and male are similar while prescriptive stereotype explicates that the beliefs shared by the female and male needs to be similar. The differences in both patterns is causing discernment about the female leaders (Vázquez-Cupeiro, 2021). The theory of regulatory focus discuss that the factor of enviously badly influence the alliances of work setting. It propose that jealousy results in gains and no gain which is letting down the female staff of the company and developing the culture of queen bee (Thiranagama, 2021). The social distance theory of power determines that the female at the upper rank choose to indulge in tasks that result to keep up distance as of subordinate (Magee \& Smith, 2013). The reason of this is the female leader independence and undependability on the female staff (Suharnomo, 2019). The concept of dis identification is linked with the challenges that are faced by the individual when he/she distance from others who are from their business or organization (Yue \& King, 2021). The dis identification is harmful because it cause dissatisfaction and detachment that separate the dis identified individual from the whole group. In the case of queen bee the female leader also dis identify herself from the female staff (Baloch et al., 2021). The perspective of Meritocratic explains the managerial and communal stances avoiding the role of gender for encouraging in the operations of firm. The viewpoint of equal opportunities focus on providing unbiased perquisites to female which leads towards their success and help them to reach at top ranks (Lepe et al., 2021). The outlook of special contribution highlights that the female leaders are concerned about the success and growth of subordinate female. The perspective of alternative values intents to improve the conditions for female to work and working with the subordinate with coordination (Lepe et al., 2021). The attitude theory is describes the stereotypical attitudes and responses of both genders (Breckler \& Wiggins, 1989). The theory suggested that the stereotypes regarding the female are more while it is compared with male (Magee \& Penfold, 2021). The assumptions 
about the female leaders of the company that is perceived by the female staff is effected by the relational role of gender. The firms in which female dominance exists has high relational eminence (Magee \& Penfold, 2021). The literature review revealed un-constructive relation in the female working in the firms. The issues of enviously, deleterious and toxic association have been found in the research which give raise to phenomena of queen bee. Nonetheless, the literature suggest the need to explore the phenomena that the female leaders adopt culture of queen bee because of the environment of the firm since it is a male dominant sector and examine the relation in the female leaders and female staff that whether it is cooperative or suppressive in the Pakistani banking industry. Pakistan banking sector is male dominant that has long hours of working and hard-hitting targets to be achieved such environment is making it difficult for female interconnect with the staff (Kobus-Olawale et all., 2021). Numerous researches concluded that in banking sector the female staff feel confident in the presence of female leader which is diminishing the effect of queen bee (Harvey, 2018). Another research showed that as the participation of the female has been increasing in the banking sector the women are becoming supportive to their juniors and reducing the gender biasness by acting as a role model instead of being a queen bee (Arvate et al., 2018). Since the participation of women in the banking sector is increasing which raised the need to study the phenomena of queen bee in banks.

\section{Methodology}

Qualitative approach was used to explore the prevalence of the phenomena of queen bee in the banking industry of Pakistan. The design of research was phenomenological for examining the lived experiences of the female leaders as well as the female staff regarding the syndrome of queen bee. This design was used for understanding the personal perception and views of the participants of the research about the phenomena under study. The population of the study was the financial institutions such as the private banks operating in the city of Lahore, Pakistan. The private sector banking institutes were selected because it has setting that is male dominant. The sampling strategy used in the study was non-probability purposive sampling. The reason for using this technique was to reach the targeted participants. The sample size in qualitative research is not concerned since the saturation point was obtained by the researcher. Total sixteen interviews were conducted. The banks from where the interviews were conducted was four top and well-established private banking institutions operating in Lahore which are Silk Bank, Bank Alfalah, Faysal Bank and United Bank Limited (UBL). The five women at the upper management positions such as the district manager and regional manager were interviewed. The six female were selected from the middle rank of managerial position such as the area sales executives and branch directors. The five women who were working at entry level such as the cashier, relationship officer and service representatives were also interrogated. In order to collect the data, semi-structured interviews were used. The data obtained by conducting interview from the female leader in one bank was also cross checked by interviewing the female staff of that banking institutions. Women from different level of hierarchy were carefully chosen for getting insight about the syndrome of queen bee from female leader as well as from the female subordinate to understand their point of view and perception. The interview guideline was developed in accordance with the questions of the research study. While conducting interview, probing questions were asked to get an in-depth insight about the topic of research. There was a separate interview guide for the female leaders and female staff so that a clear view about the issue of study can be gathered from both. The permission of the participants were obtained before recording the interviews. The audio-typed interviews were transcribed using the approach of verbatim. Then the data was analyzed. For analysis purpose, using the data different codes were generated. On the basis of the codes, the categories were developed that led towards broader qualitative themes which was depicting the major findings of the research study. While analyzing the data, it was focused that the researchers opinion do not create any biasness along with this, the confidentiality of the participant was taken into account so that any data of the 
respondent is kept private and not used for any other purpose other than the research in hand.

\section{Data Analysis}

From analyzing the data, three major themes of the study has been emerged that is further divided into sub themes and presented here:

\section{Influential Role of Women at the Work Setting Experiences of Women Leaders and Women Staff}

The participant of the study was female leaders and female staff working in the banking institutions of Lahore. The leaders and subordinates were asked about their experience working with the female bosses. Almost all the female subordinate respondents shared their views that female leaders are motivating and supporting them. The respondents mentioned that their female bosses are making positive changes in the work place. When the female reach at the upper rank, she makes every effort that the environment in the company is better for the female staff to work. One of the respondent said:

"Times have changed now; females are very supportive with each other" (R3)

Talking about the female leader or subordinate, the response of the respondents showed that all the women support each other because it is in the nature of the female that she treats all the people equally whether she has reached at the upper managerial level or working at entry level. One of the respondent mentioned that her female supervisor fought for her promotion that was long delayed and she get promoted just because of the women boss. When the women achieve high level of position and managerial rank in the company it makes them supportive for other women and making ways for their female coworkers to be successful and reach at better positions. The respondent also stated that female leaders are influencing and inspiring them to work hard and reach at the higher level of management. The female leaders are also reducing the gender discrimination in the company. One of the female leader shared her experience that in past the women bosses were not showing any support to the female colleagues but now the attitude of the women leaders has changed and they do not suppress their women staff. The respondent shared her views:

"When I was working as a sub-ordinate female I have not seen any support by the females but in this era when I am myself a leader and in my batch there are many females who are at leadership position, I have seen all of them promoting and supporting the other female staff. But at my time, I don't know there was insecurity in the females". (R1)

The participants were interrogated about the style of leadership which is adopted by the female supervisor in their financial institution. Most of the females agreed that the style of the female boss is authoritative since in order to get the task done and it is important that the female have an authoritarian attitude. One of the female respondent told:

"This is a male dominated society. If female leaders would not follow authoritative leadership style, no one will take her serious. She has to be a little bossy, so that she gets the tasks accomplished."(R10)

So, it is concluded from the responses that in past female leaders was jealous and insecure from the female staff but now there is no factor of envy and female staff is getting support from their supervisors by acknowledging and appreciating their efforts. The gender inequality and gender discrimination is also reduced by the female at top ranks. The female leaders are also inspiring their staff to work hard for achieving the top position.

\section{Women Inclination for Working with Staff Women} Progression of Women 
As the ratio of women in the banking sector is increasing, it is beneficial for the other women who are entering in the banks as employees. The women bosses has made numerous changes in the work setting which is creating a better place and environment for female to work in the sector that has dominance of male. When the female respondents were questioned about the fact that the female bosses are brought benefits in the company, almost all the participants agreed that the changes women supervisors are brought up in the organization is helpful for the other women colleagues. One of the female said:

"Definitely yes, because women are themselves inculcating this women culture and they are trying to change the mind set as well. They are trying to promote the females more than the men. So yes, now the women at senior positions are making difference in this industry." (R2)

The participants revealed that there has been seen increase in the recruitment of the women in the banking institutions which is also one of the reason of the female progression. When the female is hired in an organization in which she has a female boss, her expectations from the women supervisor increase as compared to male leader. The female expect that the female boss will understand her situation and help her to get through the hard times. The respondent shared her point of view by adding to the discussion about the female supervisor:

"Being a female, I expect that she should understand her female employees and their problems better than a male boss. She should provide us enough confidence and comfort so that we can share any of our personal problems with her. She should understand that being a female we can also have some issues." (R16)

Same response was highlighted from the female bosses that the subordinates are expected to work hard so that they can break the glass ceiling and be successful. The female leaders said that they are working with their subordinate females by helping them out in their tasks and also solving the difficulties that they are facing so that a better work life balance is maintained by the female staff. The female leader said:

"As I am senior to someone, I always treat them like my children. I consider that it is my responsibility to guide and coach them." (R15)

So from the answers of the participants it is concluded that the female advancement is increasing in the banking sector because the women are recruited in the banks without any discrimination which is also leading towards creating easiness for the female to work. The female bosses being a role model encourage the female staff and also take stand for them. These all factors are adding towards the progress and development of the female.

\section{Better Environment of Working for Women}

For the purpose to provide better environs for the female to work, it is important that the female are provided a safe and secure place in which the female can work without any difficulties and problems. The female subordinates shared that the female supervisor is supportive and encouraging which results in increasing their motivation and accomplishing their goals and objectives. When the female gets support from the other female it gives her a sense of motivation and realization that her efforts are being valued and appreciated by her leader. One of the participant stated:

"The good thing is that when a female realizes that she understands your issue which you cannot discuss with a male. So this thing gives you a lot of motivation and you feel that you can work even harder for that person and to achieve the goals as well. Female to female support encourages you as well and gives motivation that you have some ones back."(R7)

The participants of research when cross-examined about their preferences to work with the 
female manager or male manager, most of the subordinates choose to work with the women as their leader. According to the responses of the participants highlighted that the interaction with the female manager is quite easy and comfortable while it is compared with the male bosses. The response of the female subordinate is explaining her experience about the women leader, as she said:

"Communicating with females is far better than communicating with males. You can share all you problems easily with them. Every worker is from a different family background with different domestic problems. Female workers feel hesitant to talk about these with male bosses. They cannot convey their message to males properly as compared to females." R10)

The theme concluded that the women are coming across a better environment of working in the supervision of the female leader who are encouraging and motivating the female subordinate. The support of the female boss is playing a crucial role in the development of other staff. The responses also stated that toady the female staff is more inclined towards working with the woman boss rather than male boss.

\section{Phenomena of Queen Bee Syndrome as a Gender Based Stereotype Male Dominated Culture}

The culture in the banking sector is male dominated due to this the male are given more opportunities to be at the top ranks as compared to woman. The participants of study when asked about glass ceiling, they mentioned that they faced this and they are not promoted because of the male dominance. The respondent said that:

"I have faced such time as well where a non-performer male got promoted just because he was a male not because of his performance." (RI)

Most of the respondents mentioned that it is the mentality of the men that is creating a lot of fuss for the females. As when the female achieve high rank, her character is blamed that she must have any links with the upper managers that is why she is promoted. All the participants said that gender based stereotype is prevailing in the banking division. As the responses of the female clarified that the men do not bear that the female is reaching at high levels so they get jealous of them and spread such myths about their character and nature. One of the respondent told:

"In fact, it is due to the mentality, males of the organization are holding. The typical mindset of men is now gradually changing. Usually, men think that women are confined for bringing up and giving birth to children." (R12)

Another respondent said:

"If women are at the leadership position, the males turn this thing straight to the character of females that this growth is not because they are worthy. Their character is not good and they are getting promotions because of that. Basically, the problem is of acceptability. They cannot accept that a female is leading them. This is a typical mindset of sub-continental countries." (R1)

From the answers of the participants it is concluded that the female are facing numerous issues because of the culture of banking sector that male dominant. The gender based stereotype which is hold by the male about the female is creating problems for them.

\section{Manly Approach in Banking Institutions}

The banking sector is a division in which the male approaches are used. The mindset of male about the female is that they cannot work with one another since they are jealous of each other and backbite about their female co-workers. When the respondents were asked about the phenomena of queen bee, most of the participants mentioned that it is the typical mindset of the male that is creating such stereotypes, in actual it is not prevailing in the work setting. The respondents stated that it is difficult to work in such an environment in which the male is always 
looking up for any mistake and they trigger you. The politics of men in the banking sector is giving raise to the gender based myths. One respondent said that:

"Men actually promote rivalry among women. They think that women will only work when there would be a natural jealousy and rivalry among them, otherwise they will only get themselves involved in gossips." (R12)

Another female said:

"I have seen this type of culture here that men usually promote women rivalry. I have also seen bosses who take advantage of the situation." (R14)

The answers of the female participants conclude that the phenomena of queen bee is actually endorsed by the male mindset and it is not really prevailing in the banking sector of Pakistan and it is the environment in the company that is raising such stereotypes.

\section{Women to Women Acceptance}

The women working in the different positions in the banking institutions are showing acceptance to the other female this is the reason that the female is getting promoted and inspiring the other females too. The role of education cannot be denied in this respect because educated women prefer solidarity instead of competition. The responses of the participants revealed that al of the female whether they are the female supervisor or female subordinate, all of them have positive perception about each other. The subordinate women agreed that their leaders are not suppressing them and not creating any kind of hurdles in our success at the same time the supervisors also stated that they support their staff. The views of one participant stated:

"All females supporting each other can make things easy for other females and can create a positive image that females can work better." (R7)

Keeping in view the responses of all the participants, it is very obvious that female leaders are nurturing their female subordinates and instead of overpowering them they are giving motivation and encouragement to the female staff.

\section{Discussion}

The major findings of the study indicated that in past the women bosses used to be unsupportive and uncooperative. Since the time has changed that also changed the attitude of the female leaders about their female staff. Now they show a great level of support and encourage the female colleagues so that they can achieve high ranks. The findings of the study is not showing relevance with the literature, because the previous studies showed that the women supervisors are suppressing the female and creating hurdles in their progress (Derks et al., 2016). Keeping in view the answers of the female participants, it seems that the phenomena of queen bee is not actually prevailing in the banking institutions, it is only the male that are spreading such kind of myths about the female leaders. This is a gender based stereotype that is not existing in the women but it is the environment of the banks which is male dominant that gives raise to gender politics. The results are consistent with the different previous researches that the phenomena of queen bee is just a myth that has been developed by the male dominated culture (Webber \& Giuffre, 2019). The findings of the research revealed that the female leaders are benefiting the female staff in different ways by inspiring and motivating their co-workers and being a role model from them to reach at top ranks. The literature review also highlighted that the women are showing support to their female colleagues and there has been seen female to female acceptance but due to the environment of the workplace effects the attitude of the women bosses (Glass \& Cook, 2016). From the perspective of the respondents, it gives the impression that even if the women are capable enough to be at top ranks but the male consider it as they have links with the bosses due to which they are getting promoted. Such mindset of male creates hurdles for women to achieve high position. The previous studies revealed that the stereotypical approach about the women cause problems for females in the organization (Hurst et al., 2016). The crux of the 
findings show that the phenomena of queen bee is part of the sexual politics and it is a gender based stereotype which is developed by the male dominated setting, whereas, female supervisors are promoting their female subordinate that is adding towards the advancement of female.

\section{Conclusion}

The study has addressed the issue of queen bee phenomena in which the females are selected as frontrunners and leaders in the company that result in lessening the success opportunities for other female staff while its compassion is made with the organizations in which male are at top positions. The phenomena determined that it is not male who hold back the female but it is female at upper and leadership position who limit their growth and development. Female bosses are guiding and motivating their co-workers and similarly the female subordinate are also focusing to achieve high ranks by accomplishing their goals. The phenomena of queen bee is not believed by the females in the banking institutions of Lahore, Pakistan as the female bosses are standing with their subordinate and playing the role of their ideal along with helping them to develop and reach at top levels. The acceptance of female to female is existing in the banks. But talking about the culture of the banking sector that has a male dominance approach it is unconducive for the female, because the competition in the banks is because of the environment of the work setting as male in the organization is giving raise to the stereotypes of queen bee that is initiating deterrent in the growth of female. There are certain limitation of this study. One of the limitations of the research is the sample size since the banks from Lahore were selected. The time and resources were also a constraint of the study. The data was collected at one time which is why the detailed information about the phenomena is missing. Instead of selecting different industries to examine the topic under study only the banking sector was selected to explore the queen bee culture. The approach to collected data was qualitative which has chances of subjectivity. Only private banks were taken in sample not the public banks. The future researcher can increase the size of sample and conduct research on different cities and compare their data. The longitudinal approach can be used to collect the data in future. The sector other than banking industry can be selected to explore the phenomena. The mixed method technique can be used to get a full in-depth insight about the prevalence of the queen bee culture. The public sector banks can be included in the population and comparison can be made between the results of the private and public banks. The study has also certain implications. The research study is providing valuable implications to the women working in the banking institutions for increasing their awareness about the gender related stereotypes and coping up with the mindset of the male dominated culture. The study is helpful for the HR in recruiting women to add value in their organization. It is useful for the financial institutions/policy makers/regulators to make policies about eliminating the gender politics as well as stereotypical approach in the organization to create a better environment of working to the female. It is helpful for the organization in monitoring the participation of female and the intra-gender relationship between the female at the workplace. The study is also beneficial for firms in adding the female in the workplace because women have flexible attitude towards all type of work environment and gives innovative ideas and challenging the status quo of male dominance.

\section{References}

Arvate, P. R., Galilea, G. W., \& Todescat, I. (2018). The queen bee: A myth? The effect of toplevel female leadership on subordinate females. The Leadership Quarterly, 29(5), 533-548.

Babalola, O. O., du Plessis, Y., \& Babalola, S. S. (2021). Insight into the organizational culture and challenges faced by women STEM leaders in Africa. Social Sciences, 10(3), 105.

Baloch, M. N., Samo, A. H., Bhatti, A. A., Bhughio, M. B., \& Zeb, S. (2021). Position and Prejudice: Exploring the Stereotypical Transformation of Female Identity at Workplace. ETIKONOMI, 20(1), 137-152.

Baumgartner, M. S., \& Schneider, D. E. (2010). Perceptions of women in management: A thematic analysis of razing the glass ceiling. Journal of Career Development, 37(2), 559-576. 
Billing, Y. D., \& Alvesson, M. (1989). Four ways of looking at women and leadership. Scandinavian Journal of Management, 5(1), 63-80.

Breckler, S. J., \& Wiggins, E. C. (1989). On defining attitude and attitude theory: Once more with feeling. Attitude Structure and Function, 407-427.

Corwin, E. S., Loncarich, H., \& Ridge, J. W. (2021). What's It Like Inside the Hive? Managerial Discretion Drives TMT Gender Diversity of Women-Led Firms. Journal of Management, 01492063211011755.

Countrymeters (2021). Pakistan population live. Retrieved from Countrymeters.com: https://countrymeters.info/en/Pakistan

Da Rocha Grangeiro, R., Silva, L. E. N., \& Esnard, C. (2021). I broke the glass ceiling, now what? Overview of metaphors to explain gender inequality in organizations. International Journal of Organizational Analysis.

da Rocha Grangeiro, R., Rodrigues, M. S., Silva, L. E. N., \& Esnard, C. (2019). Scientific Metaphors and Female Representativeness in Leadership Positions: A Bibliometric Analysis. Revista Psicologia: Organizações \& Trabalho, 21(1), 1157-1166.

Derks, B., Ellemers, N., Van Laar, C., \& De Groot, K. (2011a). Do sexist organizational cultures create the Queen Bee?. British Journal of Social Psychology, 50(3), 519-535.

Derks, B., Van Laar, C., \& Ellemers, N. (2016). The queen bee phenomenon: Why women leaders distance themselves from junior women. The Leadership Quarterly, 27(3), 456-469.

Derks, B., Van Laar, C., Ellemers, N., \& De Groot, K. (2011b). Gender-bias primes elicit queenbee responses among senior policewomen. Psychological Science, 22(10), 1243-1249.

Desk, W. (2021). Pakistan's population has ballooned to $207.68 \mathrm{mn}$, shows census 2017 report. Retrieved from Daily Pakistan.com: https://en.dailypakistan.com.pk/19-May-2021/pakistans-population-has-ballooned-to-207-68mn-shows-2017-census-report

Drexler, P. (2013). The tyranny of the queen bee. The Wall Street Journal, 6(6), 8.

Eagly, A. H., \& Karau, S. J. (2002). Role congruity theory of prejudice toward female leaders. Psychological Review, 109(3), 573.

Ebrahimi, E. (2021). Understanding the Meaning of Queen Bee Syndrome Phenomenon from the Perspective of Women Working in a Public University: A Descriptive Phenomenological Approach. Public Organizations Management, 9(2), 31-46.

Faniko, K., Ellemers, N., \& Derks, B. (2021). The Queen Bee phenomenon in Academia 15 years after: Does it still exist, and if so, why?. British Journal of Social Psychology, 60(2), 383-399.

Fleischer, D. (2021). Does gender diversity in supervisory boards affect gender diversity in management boards in Germany? An empirical analysis. German Journal of Human Resource Management, 2397002221997148.

Formanowicz, M. (2021). Why Documenting Every Gender Bias Counts: A Short Commentary. Social Psychological Bulletin, 16(1), 1-8.

Gallardo-Pérez, J., Romero-Moraleda, B., Paredes-Hernández, V., \& León-Quismondo, J. (2021). The Glass Ceiling in the Sport Industry: Spanish Version of the Women as Managers Scale (WAMS). Sexes, 2(2), 163-173.

Glass, C., \& Cook, A. (2016). Leading at the top: Understanding women's challenges above the glass ceiling. The Leadership Quarterly, 27(1), 51-63.

Harvey, C. (2018). When queen bees attack women stop advancing: recognising and addressing female bullying in the workplace. Development and Learning in Organizations: An International Journal, 32(5), 1-4.

Kasem, M. J. (2021). Women's Willingness to Support Other Women in the Workplace (Doctoral dissertation, Baker College (Michigan)).

Kobus-Olawale, J., Schachtebeck, C., \& Dhanpat, N. (2021). Investigating career progression experiences of women into top management at a South African bank. EUREKA: Social and Humanities, (3), 28-40.

Krause, W., \& Hartney, E. (2021). Gender Diversity, Unconscious Bias, and Leadership for 
Organizational and Planetary Health. Exploring Gender at Work, 161.

Lepe, R. M., Warren, M. A., \& Crano, W. (2021). I may be Latino/a but I am a citizen: Distancing from a stigmatized identity. Immigrants' Psychology, 1-38.

Levine, J. M., \& Moreland, R. L. (1994). Group socialization: Theory and research. European Review of Social Psychology, 5(1), 305-336.

Magee, J. C., \& Smith, P. K. (2013). The social distance theory of power. Personality and Social Psychology Review, 17(2), 158-186.

Magee, L., \& Penfold, R. (2021). Game of snakes and ladders: barriers and enablers for aspiring women leaders in healthcare. BMJ Leader, leader-2020.

Netshitangani, T. (2019). Queen Bee Syndrome: examining ubuntu philosophy in women's leadership. Ubuntu: Journal of Conflict and Social Transformation, 8(1), 197-203.

Piccio, B. (2021). Queen Bees, stereotypes, leadership, and gender dichotomy. Will the postpandemic festival environment be ready for a transformation?. Danish University Colleges, 417.

Scheifele, C., Ehrke, F., Viladot, M. A., Van Laar, C., \& Steffens, M. C. (2021). Testing the basic socio-structural assumptions of social identity theory in the gender context: Evidence from correlational studies on women's leadership. European Journal of Social Psychology, 51(1), e1-e16.

Sengul, H., Cinar, F., \&Bulut, A. (2019). The perception of queen bee phenomenon in nurses; qualitative study in health sector. Nigerian Journal of Clinical Practice, 22(7), 906.

Staines, G., Tavris, C., \& Jayaratne, T. E. (1974). The queen bee syndrome.

Statistics, P. B. (2018). Pakistan Employment Trends. Islamabad: Government of Pakistan Ministry of Statistics Pakistan Bureau of Statistics.

StatisticsTimes. (2021). Gender ratio in the World. Retrieved from StatisticsTimes.com: https://statisticstimes.com/demographics/world-sexratio.php\#: :text=Gender\%20Ratio\%20in\%20the\%20World\%20in,101.69\%20males\%20per $\% 20100 \% 20$ females.

Stets, J. E., \& Burke, P. J. (2000). Identity theory and social identity theory. Social psychology quarterly, 224-237.

Suharnomo, S., \& Permatasari, D. (2019). Investigating the "queen bee" phenomenon in Indonesia: a case study. Diponegoro International Journal of Business, 2(1), 41-51.

Thiranagama, W. (2021). Is gender plays a role in workplace?: Review of Glass-Ceiling Effect on Women Employees. JBFEM, 4(1), 1-8.

Vázquez-Cupeiro, S. (2021). Women's networking in Spanish academia: a 'catch-all' strategy or strategic sisterhood?. Critical Studies in Education, 1-16.

Webber, G. R., \& Giuffre, P. (2019). Women's relationships with women at work: Barriers to solidarity. Sociology Compass, 13(6), e12698.

Yue, A., \& King, C. (2021). Female Discrimination in the Workplace: Skilled Communicators But Undermined Leaders. Journal of Student Research, 10(1). 